\title{
Journal club in an ICU: rate and factors associated with practice-changing articles. Analysis of 1712 articles read over a 13-year period (2007-2019)
}

\author{
Damien Contou*, Marina Thirion, Olivier Pajot, Gaëtan Plantefève and Hervé Mentec
}

Keywords: Journal Club, Medical Journal, Continuing medical education, Intensive Care, Practice-changing article

Every day more than 2500 original articles are newly indexed in PubMed. Coping with this abyssal amount of medical information is challenging for physicians [1]. Clinicians must read the journals publishing studies having an impact on their daily clinical practices. Our Intensive Care Unit (ICU) has been running a Journal Club (JC) for many years. We aimed at assessing the proportion of practice-changing articles being analyzed during our JC meetings and at identifying factors associated with practice-changing articles.

From August 2007 to August 2019, we prospectively collected the references of articles presented at each JC meeting. Our medical-surgical ICU has 18 beds (12 intensive and 6 intermediate care beds) and our 760-bed hospital is university-affiliated. Our medical team comprises 4 attending intensivists, 3 fellows in intensive care and 7 residents. JC sessions are scheduled weekly and last from 1.5 to $2.5 \mathrm{~h}$ depending on the number of participants exposing an article (one article per participant). Participants are free to choose and expose orally an article recently published in any medical journal (general, ICU or non-ICU specialized). Presentation of an article lasts up to $10 \mathrm{~min}$ and is followed by a 5 -min discussion. Most often, only the participant who reports an article had read the article before the JC meeting. The number

\footnotetext{
*Correspondence: damien.contou@ch-argenteuil.fr Service de Réanimation Polyvalente et Unité de Surveillance Continue, Centre Hospitalier Victor Dupouy, 69, rue du Lieutenant-Colonel Prud'hon,
} 95100 Argenteuil, France of articles published during the study period was determined with PubMed. All the exposed articles were independently reviewed by two of us (DC and HM) and were considered to change practices when at least one considered they did (did this article change my daily clinical practice?)

During the study period, 313 JC meetings were held and 1712 articles from 97 journals were exposed. Median number of articles discussed per meeting was 6 [4-7]. Median number of physicians attending each JC meeting was 7 [6-8] (attendings: 2 [2-3], fellows: 1 [1-2], residents: 3 [2-3]). After removing duplicates and non-original articles, 1568 unique original articles were exposed, accounting for $0.01 \%$ (95\% CI [0.01-0.02\%]) of the 10.982.188 original articles referenced in PubMed during the same period. General, ICU and non-ICU specialized journals accounted for $32 \%, 47 \%$ and $21 \%$ of the exposed articles, respectively. Compared to general and non-ICU specialized journals, the proportion of read-over-published articles was higher for ICU specialized journals $(0.18 \%$ vs. $0.13 \%$ vs. $2.61 \%$, respectively; $p<0.0001)$.

Only 93/1568 (5.9\%) articles were considered as practice-changing. The two reviewers agreed on $95 \%$ of the evaluations. Factors associated with practice-changing articles were identified by univariable analysis and were as follows: age of the physician reporting the article (attending 7\% vs. fellow $7 \%$ vs. resident $4 \% ; \mathrm{p}=0.03$ ) and type of medical journal in which the article was published (general $9 \%$ vs. ICU specialized $4 \%$ vs. nonICU specialized $5 \% ; \mathrm{p}=0.001$ ). The year of publication 
of the article and the specialty of the physician reporting the article were not associated with practice-changing articles. Data regarding the 5 most read general, ICU and non-ICU specialized journals, accounting for $87 \%$ of the unique original articles exposed during our JC meetings, are detailed in Table 1.

The proportion of articles exposed during our JC meetings appears paltry $(0.01 \%)$ compared to the huge amount of literature published every year. Only $5.9 \%$ of the exposed articles were considered as practice-changing. Similarly, it was recently reported that among 1240 articles assessing the impact of any intervention on mortality of ICU patients, only 27 showed a reduction, i.e., 2.2\% [2]. General journals appear to publish a higher proportion of practice-changing articles compared to ICU or non-ICU-specialized journals. Indeed, the 27 articles reported as decreasing mortality of ICU patients were more often published in general journals
(55\%) than in ICU-specialized (30\%) or non-ICU-specialized (15\%) journals [2].

Limitations of our study include that physicians did not read articles only for JC and may read more than one article to prepare JC. Therefore, our data underestimate the real figure. Moreover, all the articles exposed during our JC meetings did not focus only on the ICU practices, potentially responsible for an underestimation of the rate of practice-changing articles. It is also likely that JC participants were more prone to choose articles considered as practice-changing, and this selection bias overestimates the clinical impact of medical journals. Last, practice-changing was subjectively assessed by only two of us limiting generalizability.

In a French university-affiliated ICU with regular JC meetings, exposed articles were a drop in the ocean of medical literature and the proportion of practice-changing articles appeared minor. Of course, other sources of continuing medical education can be used [3], but it is

Table 1 Number of original articles published from August 2007 to August 2019 in the 5 most read journals during our journal club meetings in the 3 journal categories, percentages of articles exposed during our journal club meetings and percentages of practice-changing articles

\begin{tabular}{|c|c|c|c|c|c|}
\hline Journals $(n=97)$ & $\begin{array}{l}\text { Nb original } \\
\text { articles } \\
\text { published }\end{array}$ & $\begin{array}{l}\mathrm{Nb} \text { original } \\
\text { articles read }\end{array}$ & $\begin{array}{l}\%[95 \% \mathrm{Cl}] \mathrm{read} / \\
\text { published articles }\end{array}$ & $\begin{array}{l}\mathrm{Nb} \text { of original } \\
\text { practice-changing } \\
\text { articles }\end{array}$ & $\begin{array}{l}\%[95 \% \mathrm{Cl}] \text { of original } \\
\text { practice-changing read } \\
\text { articles }\end{array}$ \\
\hline General journals $(n=15)$ & 294,167 & 495 & $0.17[0.15-0.18]$ & 45 & $9.09[6.86-11.95]$ \\
\hline New England Journal of Medicine & 8534 & 215 & $2.52[2.21-2.87]$ & 25 & $11.63[8.00-16.60]$ \\
\hline Journal of the American Medical Association & 8678 & 135 & $1.56[1.32-1.84]$ & 9 & $6.67[3.55-12.18]$ \\
\hline The Lancet & 10,426 & 71 & $0.68[0.54-0.86]$ & 9 & $12.68[6.81-22.37]$ \\
\hline British Medical Journal & 12,488 & 21 & $0.17[0.11-0.26]$ & 0 & $0.00[0.00-15.46]$ \\
\hline Archive of Internal Medicine & 1653 & 19 & $1.15[0.74-1.79]$ & 0 & $0.00[0.00-16.82]$ \\
\hline Others $(n=10)$ & 252,388 & 34 & $0.01[0.01-0.02]$ & 2 & 5.88 [1.63-19.09] \\
\hline ICU specialized journals $(n=12)$ & 29,553 & 728 & $2.46[2.29-2.65]$ & 31 & $4.26[3.02-5.98]$ \\
\hline Critical Care Medicine & 4927 & 361 & $7.33[6.63-8.09)$ & 15 & $4.16[2.53-6.74]$ \\
\hline Intensive Care Medicine & 3014 & 200 & $6.64[5.80-7.58]$ & 7 & $3.50[1.71-7.05]$ \\
\hline $\begin{array}{l}\text { American Journal of Respiratory and Critical } \\
\text { Care Medicine }\end{array}$ & 4926 & 77 & $1.56[1.25-1.95]$ & 3 & $3.90[1.33-10.84]$ \\
\hline Critical Care & 4268 & 57 & $1.34[1.03-1.73]$ & 4 & $7.02[2.76-16.70]$ \\
\hline Annals of Intensive Care & 692 & 16 & $2.31[1.43-3.72]$ & 1 & $6.25[1.11-28.33]$ \\
\hline Others $(n=7)$ & 11,726 & 17 & $0.14[0.09-0.23]$ & 1 & $5.88[1.05-26.98]$ \\
\hline Non-ICU-specialized journals $(n=70)$ & 264,429 & 345 & $0.13[0.12-0.14]$ & 17 & $4.93[3.10-7.75]$ \\
\hline Clinical Infectious Diseases & 7661 & 76 & $0.99[0.79-1.24]$ & 7 & $9.21[4.53-17.81]$ \\
\hline Chest & 5102 & 65 & $1.27[1.00-1.62]$ & 2 & $3.08[0.85-10.54]$ \\
\hline Anesthesiology & 3613 & 23 & $0.64[0.42-0.95]$ & 1 & $4.35[0.77-20.99]$ \\
\hline The Lancet Infectious Diseases & 2369 & 18 & $0.76[0.48-1.20]$ & 1 & 5.56 [0.99-25.76] \\
\hline Annals of Surgery & 4259 & 14 & $0.33[0.20-0.55]$ & 1 & 7.14 [1.27-31.47] \\
\hline Others $(n=65)$ & 241,425 & 149 & $0.06[0.05-0.07]$ & 5 & $3.36[1.44-7.61]$ \\
\hline $\begin{array}{l}\text { Original articles published in journals } \\
\text { read at least once during our journal } \\
\text { club meetings }\end{array}$ & 588,149 & 1568 & $0.27[0.25-0.28]$ & 93 & $5.93[4.87-7.21]$ \\
\hline $\begin{array}{l}\text { All original articles referenced on } \\
\text { PubMed }\end{array}$ & $10,982,188$ & 1568 & $0.01[0.01-0.02]$ & 93 & $5.93[4.87-7.21]$ \\
\hline
\end{tabular}

$\mathrm{Nb}$ number, $\mathrm{Cl}$ confidence interval 
also possible to increase the profitability of JC by following published recommendations [4].

\section{Abbreviations}

ICU: Intensive Care Unit; JC: Journal Club.

\section{Authors' contributions}

DC and HM are responsible for the conception and design. All the 5 authors were responsible for the data acquisition, analysis and interpretation. DC takes responsibility for the paper as a whole. All authors read and approved the final manuscript.

\section{Funding}

No funding.

\section{Availability of data and materials}

The dataset used and analyzed for the current study is available from the corresponding author on reasonable request.

\section{Ethics approval and consent to participate}

This observational, non-interventional analysis of non-medical data and not involving patients did not require ethics approval or consent to participate.

\section{Consent for publication}

Not applicable.

\section{Competing interests}

The authors declare that they have no competing interests.

Received: 28 April 2020 Accepted: 25 May 2020

Published online: 01 June 2020

\section{References}

1. Bastian H, Glasziou P, Chalmers I. Seventy-five trials and eleven systematic reviews a day: how will we ever keep up? PLoS Med. 2010;7:e1000326.

2. Santacruz CA, Pereira AJ, Celis E, Vincent J-L. Which multicenter randomized controlled trials in critical care medicine have shown reduced mortality? A systematic review. Crit Care Med. 2019;47:1680-91.

3. Keeping Up with the Medical Literature | NEJM Resident 360 |. https:// resident360.nejm.org/content_items/keeping-up-with-the-medical-liter ature.

4. Deenadayalan Y, Grimmer-Somers K, Prior M, Kumar S. How to run an effective journal club: a systematic review. J Eval Clin Pract. 2008;14:898-911.

\section{Publisher's Note}

Springer Nature remains neutral with regard to jurisdictional claims in published maps and institutional affiliations.

\section{Submit your manuscript to a SpringerOpen ${ }^{\circ}$ journal and benefit from:}

- Convenient online submission

- Rigorous peer review

- Open access: articles freely available online

- High visibility within the field

- Retaining the copyright to your article

Submit your next manuscript at $\gg$ springeropen.com 